\title{
Perceived Spousal Support and Beliefs Toward Cervical Smear Screening Among Chinese Women
}

\author{
Su-I Hou \\ The University of Georgia, Athens
}

\begin{abstract}
Objective: Family is a major part of the social support network in Chinese society. This study examines the role of Chinese women's perceived support from spouse on their cervical cancer screening beliefs and intention. Design: Participants were recruited from female family members of inpatients admitted to one of the major teaching hospitals in Taiwan $(n=424)$. Screening intention, beliefs (perceived pros, cons, risk, and norms), and demographics were assessed via a self-administered survey. Women were classified into two groups based on their perceived spousal support towards having a cervical smear screening (low versus high). Results: Mean age of the sample was 34 years, $28 \%$ did not have high school education, $37 \%$ expressed no screening intention in the next 12 months, and $58 \%$ perceived their general health to be fair or poor. Women who perceived lower spousal support were more likely to be those without high school education (39\% vs. $21 \%$ ) or with lower perceived health status ( $65 \%$ vs. $54 \%)$. After adjusting for these demographic variables, multiple regression analyses revealed that women who perceived lower spousal support were associated with lower perceived benefits $(B=-.210, p<.001)$, higher barriers $(\mathrm{B}=.228, \mathrm{p}<.001)$, and lower norms towards cervical smear screening $(\mathrm{B}=-.127, \mathrm{p}=.012)$. On the other hand, women who perceived higher spousal support were associated with positive intention to screening $(\mathrm{OR}=1.94 ; 95 \%$ C.I. $=[1.28,2.95])$. Conclusion: The study shows that perceived spousal support could be an important factor that influences various beliefs towards cervical smear screening among Chinese women. Future research should consider examine factors associated with spousal support, as well as its impact on screening adoption among different ethnic groups. The current finding has implications on intervention programs targeting spouse or significant others on promoting gynecological cancer screenings among Asian women.
\end{abstract}

(C) 2006 Californian Journal of Health Promotion. All rights reserved.

Keywords: spousal support; cervical smear; screening beliefs; Chinese

\section{Introduction}

Although cervical smear tests have been proven to be an effective screening method of detecting cervical cancer at an early stage, existing data suggest that Asian women do not have regular screenings. The prevalence of cervical smear among Asian women in the United States ranges from $40 \%$ to $56 \%$, as compared to over $90 \%$ in other groups (Chen, Diamante, Kagawa-Singer, Pourant, \& Wold, 2004; Hiatt, Pasick, Stewart, Bloom, Davis, Gardiner et al., 2001). Among Chinese women in Taiwan, the few existing studies reported similar low rates of cervical smear test utilization, ranging from $58 \%$ to $62 \%$ (Hou, Fernandez, Baumler, Parcel, \& Chen,
2003; Lee, Kuo, \& Chou et al., 1997; Wang \& Lin, 1996).

Social support has been found to be important to cervical cancer screening. Social support at worksite has shown positive relationships to some health behaviors including cervical cancer screening among blue-collar women workers (Kelsey, Campbell, Tessaro, Benedict, Belton, Fernandez et al., 2000). Recommendations from physicians were also associated with higher cervical smear screening adoption among women with diverse cultural background in Australia (Kelaher, Gillepsie, Allotey, Manderson, Potts, Sheldrake et al., 1999). In addition, women who have close friends they 
could discuss health issues with reported higher prevalence of being screened for cervical cancer (Seow, Huang, \& Straughan, 2000). Although the relationship of social support from various sources and cervical cancer screening behaviors has been examined in some studies, few have specifically discussed the influence of family or spousal support. Yang and colleagues (1994) were one of the few specifically examined family influences on cancer screening participation in seven communities in Taiwan. Study results showed that family's encouragement $(\mathrm{OR}=1.85)$ had a positive association on screening participation. Nevertheless, current knowledge on the influence of spousal support to gynecological screening such as cervical cancer is scarce.

Some existing qualitative studies have indicated the importance of family support among cancer survivors, and few have specifically examined support perceived by women with gynecologic cancers. In a qualitative study conducted by Chan and colleagues (2001), female cancer survivors indicated the importance of relationships with family while traveling through the cancer trajectory (Chan, Molassiotis, Yam, Chan, \& Lam, 2001). Women who have gynecological cancers but with poor social support are more likely to have various psychological symptoms persist over a period of time (Petersen, Graham, \& Quinlivan, 2005). In a qualitative multiethnic study conducted in Los Angeles, researchers found that social support was identified as a key socio-ecological fact. However, perceptions of support from different source were different among Caucasian versus Asian cervical cancer survivors. Key informants who work with Caucasian survivors tend to view support from friends as most important, followed by family and spousal support. In addition, balancing social support with independence (i.e., not becoming too dependent on the family) is also viewed to be essential. In contrast, informants who work with Asian cancer survivors noted that these women view spousal support as essential, while support from other family members and friends is also important (Ashing-Giwa, Kagawa-Singer, Padilla, Tejero, Hsiao, Chhabra et al., 2004). Another study examined Chinese patients undergoing cancer surgery and concluded that spouse and family members represented the largest source of social support network among these Chinese (Chan, 2004).

Most of the existing studies on cervical screening intervention program target individual variables such as personal background characteristics, beliefs, knowledge, or acculturations; and sometimes health care access issues such as transportation, language barriers, or provider's gender (Hou, Fernandez, \& Parcel, 2004; Jackson, Taylor, Chitnarong, Mahloch, Fischer, Sam et al., 2000; Sohn \& Harada, 2005). Much progress has been made to increase cervical smear screening among Asian women. Yet, screening adherence among this group is still far from satisfactory. More research is needed to explore the relationship of family's role, in particular, spousal support, to motivate and influence women's screening decision.

The purposes of the current study are to: (1) describe characteristics of women who tend to perceive lower spousal support towards having a cervical cancer screening; and (2) describe the relationships of perceived spousal support on Chinese women's cervical cancer screening beliefs and intention. Lessons learned from the study will help close our knowledge gap on the influence of perceived spousal support and women's gynecological cancer screenings, such as cervical cancer screening, among Chinese women. Findings will also help provide insight for promoting cancer screening among Asian women including Chinese.

\section{Methods}

\section{Sample}

Study participants were recruited from female family members of inpatients admitted to one of the major teaching hospitals in Taiwan during fall 1999. Participants were recruited for a controlled randomized trial study of a cervical smear screening program. Only screening nonadherent women were recruited in the study. According to the National Health Insurance Plan in Taiwan, annual cervical smear tests were provided free as part of the health care coverage to women aged over 30 years old, or younger if married. Thus, screening non-adherent women 
in the current study was defined as women who had not had a cervical smear screening in the past 12 months and who were over 30 years old, or younger if married. Details of the recruitment process is documented elsewhere (Hou, Fernandez, Baumler, \& Parcel, 2002). This research was conducted with the approval of Committee for the Protection of Human Subjects (CPHS) at The University of Texas Houston Health Science Center, School of Public Health (HSC-SPH-99-013).

\section{Measures}

This study examined the influence of perceived spousal (or partner) support towards women's cervical smear screening on women's screening beliefs and intention. Perceived spousal support towards screening was measured by asking women to rate the following item: "My husband (or partner) would not support me to have a cervical smear" on a five-point Likert scale, with response categories raged from "strongly disagree" to "strongly agree". To facilitate more straight-forward interpretation of analysis, this item was reverse-coded so that a higher rating would indicate higher perceived spousal support towards cervical smear screening. Since most women in the study were married $(90 \%)$, "spousal support", instead of "spousal or partner support", was used in this article to facilitate reading.

A set of items were developed to measure the various screening beliefs. These included: (1) fourteen items related to perceived benefits (pros) of cervical smear screening, (2) nine items on perceived barriers (cons) towards screening, (3) three items on perceived risk of getting cervical cancer, as well as (4) four items related to perceived norms of cervical smear screening behavior among women similar to their age. Similarly, for each item, responses were rated on five-point Likert scales, ranging from 1 (strongly disagree) to 5 (strongly agree). The scores of the various screening belief scales revealed overall reasonable internal consistency (Cronbach's alpha ranged from $.63 \sim .87$ ) and consistent with the underlying theoretical constructs. The process of developing this
Cervical Smear Belief Inventory (CSBI) as well as the validation of its psychometric properties is described elsewhere (Hou \& Luh, 2005).

\section{Data Analysis}

Baseline data from the intervention trial were analyzed in the current study $(n=424)$. For comparison purpose, women were classified into two groups based on their perception of spousal support towards having a cervical smear screening (low versus high), using the item median score as the cut-off point (item median $=2$ ). Demographic characteristics as well as screening beliefs and intentions among the two groups were then described and analyzed. Chisquare test was used for categorical variables and independent $t$ test was used for continuous variables. In addition, multiple regressions were used to assess the relationships of perceived spousal support on women's screening beliefs and intention, taking the demographic variables into consideration.

\section{Results}

Mean age of the sample was 34 years, 28\% did not have high school education, $37 \%$ expressed no screening intention, and $58 \%$ perceived their general health to be fair or poor. About $40 \%$ of these "screening non-adherent" women perceived very low or low spousal support towards them having a cervical cancer screening. Women who perceived lower spousal support were more likely to be those without high school education (39\% vs. $21 \%)$, perceived lower health levels (65\% vs. $54 \%)$, or being precontemplators (having no screening intention) in the next 12 months ( $49 \%$ vs. $30 \%$ ) (see Table 1 ).

Univariate analyses on women's perceived spousal support and women's screening beliefs and intention showed significant relationships. Women who perceived lower spousal support were associated with lower perceived screening benefits, higher barriers, lower perceived norm, as well as lower screening intentions. The association between perceived spousal support and perceived risk of cervical cancer was, however, not significant (see Table 2). 
Table 1

Demographic characteristics among Chinese women who perceived high versus low spousal support towards their cervical smear screening.

\begin{tabular}{|c|c|c|c|c|c|c|c|}
\hline Demographics & \multicolumn{2}{|c|}{ Perceived Spousal Support } & \multicolumn{2}{c|}{$\begin{array}{c}\text { Total } \\
(\mathbf{N = 4 2 2})\end{array}$} & $\begin{array}{c}\text { P-value } \\
{\left[\chi^{\mathbf{2}} \text { tests] }\right.}\end{array}$ \\
\hline & \multicolumn{2}{|c|}{ Low } & \multicolumn{2}{c|}{ High } & & & \\
\hline Age & $\mathbf{n}$ & $\mathbf{0}$ & $\mathbf{n}$ & $\mathbf{\%}$ & $\mathbf{N}$ & $\mathbf{\%}$ & \\
\hline Less than 30 yrs & 53 & 31.4 & 98 & 38.7 & 151 & 35.8 & $.102\left[\chi^{2}(2)=4.563\right]$ \\
\hline 20-39 years & 71 & 42.0 & 108 & 42.7 & 179 & 42.4 & \\
\hline 40+ years & 45 & 26.6 & 47 & 18.6 & 92 & 21.8 & \\
\hline Education & & & & & & & $<.001\left[\chi^{2}(2)=32.112\right]$ \\
\hline Less than high school & 66 & 39.1 & 53 & 20.9 & 119 & 28.2 & \\
\hline High school (HS) & 80 & 47.3 & 107 & 42.3 & 187 & 44.3 & \\
\hline College and above & 23 & 13.6 & 93 & 36.8 & 116 & 27.5 & \\
\hline Perceived health & & & & & & & $.025\left[\chi^{2}(1)=4.995\right]$ \\
\hline Excellent/good & 59 & 34.9 & 116 & 45.8 & 175 & 41.5 & \\
\hline Fair/poor & 110 & 65.1 & 137 & 54.2 & 247 & 58.5 & \\
\hline Screening intention & & & & & & & $<.001\left[\chi^{2}(1)=14.775\right]$ \\
\hline No & 82 & 48.5 & 76 & 30.0 & 158 & 37.4 & \\
\hline Yes & 87 & 51.5 & 177 & 70.0 & 264 & 62.6 & \\
\hline Total & 169 & 100.0 & 253 & 100.0 & 422 & 100.0 & \\
\hline
\end{tabular}

Table 2

Screening beliefs among Chinese women who perceived high versus low spousal support towards their cervical smear screening.

\begin{tabular}{|c|c|c|c|c|c|c|}
\hline & \multicolumn{4}{|c|}{ Perceived Spousal Support } & \multirow[t]{3}{*}{$95 \% \mathrm{CI}$} & \multirow{3}{*}{$\begin{array}{l}\text { P value } \\
\text { [t tests] }\end{array}$} \\
\hline & \multicolumn{2}{|c|}{ Low } & \multicolumn{2}{|c|}{ High } & & \\
\hline Screening Beliefs & Mean & SD & Mean & SD & & \\
\hline Perceived Pros (14 items) & 56.68 & 5.79 & 59.24 & 5.40 & {$[1.47-3.64]$} & $\begin{array}{c}<.001 \\
{\left[\mathrm{t}_{420}=4.63\right]}\end{array}$ \\
\hline Perceived Cons (9 items) & 27.51 & 5.24 & 24.39 & 5.23 & {$[-4.15-2.10]$} & $\begin{array}{c}<.001 \\
{\left[\mathrm{t}_{429}=5.99\right]}\end{array}$ \\
\hline Perceived Risk (3 items) & 8.44 & 2.03 & 8.51 & 2.17 & {$[-.34-.49]$} & $\begin{array}{c}.717 \\
{\left[\mathrm{t}_{420}=.36\right]}\end{array}$ \\
\hline Perceived Norm (4 items) & 15.41 & 1.96 & 15.88 & 1.93 & {$[.08-.84]$} & $\begin{array}{c}.017 \\
{\left[\mathrm{t}_{420}=2.40\right]}\end{array}$ \\
\hline
\end{tabular}


The multiple regression analyses revealed similar findings after adjusting for background variables (age, education, and perceived health status). Results showed that women who perceived higher spousal support were associated with higher perceive screening benefits $(\mathrm{B}=2.44, \mathrm{p}<.001)$, lower barriers $(\mathrm{B}=-$ $2.87, \mathrm{p}<.001)$, and higher norms towards cervical smear screening $(\mathrm{B}=.51, \mathrm{p}=.012)$. In addition, women who perceived higher spousal support were more likely to be screening contemplators (having intention to screening in the next 12 months $)(\mathrm{OR}=1.94 ; 95 \% \mathrm{CI}=[1.28$, 2.95]). Again, the regression coefficient of spousal support on perceived cancer risk was not significant. Perceived health status, on the other hand, was the only factor that revealed significant coefficient in predicting women's perceived risk of cancer. Neither age nor education showed any significant relationships with screening intention or the various screening beliefs in the multiple regression models (see Table 3).

Table 3

Multiple regression analyses of perceived spousal support towards cervical smear screening and its influence on Chinese women's screening beliefs and intention, taking demographics (age, education, health status) into consideration.

\begin{tabular}{|c|c|c|c|c|c|c|c|c|}
\hline \multirow{2}{*}{$\begin{array}{c}\text { Dependent } \\
\text { Variables } \\
\end{array}$} & \multicolumn{2}{|c|}{ Spousal support } & \multicolumn{2}{|c|}{ Women's age } & \multicolumn{2}{|c|}{ Education } & \multicolumn{2}{|c|}{ Perceived Health } \\
\hline & $\mathbf{B}$ & S.E. & B & S.E. & $\mathbf{B}$ & S.E. & $\mathbf{B}$ & S.E. \\
\hline Perceived Pros $^{\mathrm{a}}$ & $2.44 *$ & .58 & -.61 & .40 & -.03 & .41 & -.37 & .56 \\
\hline Perceived Cons $^{\mathrm{a}}$ & $-2.81 *$ & .54 & -.08 & .37 & -.52 & .39 & 1.08 & .52 \\
\hline Perceived Risk $^{\mathrm{a}}$ & .12 & .21 & -.15 & .15 & .104 & .15 & $.96^{*}$ & .21 \\
\hline Perceived Norm $^{\mathrm{a}}$ & $.51 *$ & .20 & -.18 & .14 & -.266 & .14 & -.36 & .19 \\
\hline & OR & $\mathrm{CI}^{\mathrm{c}}$ & OR & $\mathrm{CI}^{\mathrm{c}}$ & OR & $\mathrm{CI}^{\mathrm{c}}$ & OR & $\mathrm{CI}^{\mathrm{c}}$ \\
\hline Intention $^{\mathrm{b}}$ & $1.94 *$ & {$[1.28,2.95]$} & .92 & {$[.69,1.23]$} & 1.27 & {$[.94,1.73]$} & .82 & {$[.54,1.24]$} \\
\hline $\begin{array}{ll}\text { a } & \text { Multiple linear re } \\
\text { pros, cons, risk an } \\
\text { b } \\
\text { c Multiple logistic } 1 \\
\text { c } \text { CI : 95\% Confide } \\
* \text { p }<.05\end{array}$ & $\begin{array}{l}\text { sions we } \\
\text { orm). } \\
\text { ession w } \\
\text { Interval }\end{array}$ & $\begin{array}{l}\text { sed to assess } \\
\text { Ised to asses }\end{array}$ & usal & port towarc & eenir & women's & $\operatorname{nin}$ & $\begin{array}{l}\text { iefs (perceiv } \\
\text { tention. }\end{array}$ \\
\hline
\end{tabular}

\section{Discussion}

These positive relationships between spousal support and screening beliefs and intention among Chinese women are important. Current results showed that women who perceived higher spousal support had more positive beliefs towards a cervical smear screening, including perceived higher benefits, lower barriers, and higher norms. Most of the existing studies which examined the influence of spousal support focused directly on screening acceptance or participation, without measuring related screening beliefs. Although not specifically on cervical cancer screening, Seow and colleagues (1997) examined factors contributing to the acceptance of mammography screening among women in Singapore. Their data showed that the strongest independent predictor of attendance was encouragement by her spouse (adjusted $\mathrm{OR}=35.1 ; 95 \%$ CI $[18.8,65.5])$ compared with someone who had never been encouraged by another to have mammography. Similar findings regarding the influence of spouse on screening participation was also found in another study of colorectal cancers screening conducted in Australia (Forbes, Fritschi, Mendelson, Foster, 
\& Edwards, 2004). Forbes and colleagues investigated influences on participation in a community-based colorectal cancer screening by colonoscopy. They found that among participants who discussed screening with another individual, the spouse was the most common (71\%); and such discussion increased the likelihood of screening participation by $23 \%$. The current study provided additional quantitative evidence on the influence of spousal support on gynecological cancer screening beliefs among Chinese women. Furthermore, current study also revealed that those who perceived higher spousal support were almost twice likely to express intention to screening in the next 12 months $(\mathrm{OR}=1.94)$. This relationship and magnitude was consistent with an earlier study conducted by Yang and colleagues (1994) concluding that family's encouragement was positively associated to cancer screening participation $(\mathrm{OR}=1.85)$ in seven communities in Taiwan.

Current study findings have implications on interventions that address women's health through the incorporation of spouses or significant others. Data suggested that at least for some younger Chinese women, the attitudes hold by spouse towards gynecological screening such as cervical smear might worth attention. Cancer screening among Asian or Asian American women have received increasing attention, yet none of the programs has specifically target family, spouse, or significant others. Some of the strategies used among the few existing interventions or programs specifically targeting Asian women to encourage cancer screenings included: the use of media education (Jenkins, McPhee, Bird, Pham, Nguyen, Nguyen et al., 1999; Lam, McPhee, Mock, Wong, Doan, Nguyen et al., 2003), lay health workers (Bird, McPhee, Ha, Le, Davis, Jenkins et al., 1998; Lam et al., 2003), addressing organizational, economic, ethnospecific support such as the provision of services in their own language or by a female physician (Hiatt et al., 2001; Hou et al., 2004; Jackson et al., 2000; Kelaher et al., 1999; Kelly et al., 2002). These interventions or combined strategies have demonstrated some significant screening participation compared with comparison groups. To further enhance the impact of screening interventions targeting Asian women, researchers or practitioners should pay more attention to the influence of spouse or significant others, and consider working with family members in addition to the targeted women.

Furthermore, current study suggested that women with lower education or health status tend to perceive lower spousal support. This in turn, might negatively influence their screening beliefs or intention. The current finding provides information on important characteristics of women who might be at higher risk of nonadherent to cancer screening recommendations. The finding could help researchers and practitioners identify women with higher vs. lower perceived spousal support for targeted intervention programs.

One limitation of the current study was the use of single item to assess spousal support. Although study results were consistent with theoretical assumptions and existing empirical data, single item measurement could be less reliable compared with multi-item or multidimension scales. The development and use of multi-item scale to measure spousal support might help validate the relationship. In addition, interpretation of the results needs to take into account the fact that women participated in the study were mostly young. Impact of spousal support on screening beliefs or adoption among older women might be different and would need to be further examined. Finally, current study did not investigate reasons or factors that might motivate or inhibit spousal support. Future studies that examine or explore potential determinants or factors can further shed light on appropriate intervention messages and strategies.

In conclusion, current study shows that women with lower education or lower perceived health status tend to perceive lower spousal support towards cancer screening, and higher spousal support is associated with more positive screening beliefs. Results suggest that screening interventions consider working with spouse, significant others, or family members might help maximize gynecological cancer screening 
participation among Chinese and other Asian women. Family members play a pivotal role in acceptance of screening. For Asian women to be persuaded effectively to participate in screening, it would then be important to help family members see the benefits and importance of the test as well. Continued studies are need to explore potential dimensions of spousal support to develop a reliable scale, that might influence spousal perceptions or support on cervical smear screenings, and examine the significance of spousal support on cancer screening across different ethnic groups. Current study has implication on intervention programs targeting spouse or significant others on promoting gynecological cancer screenings among Asian women.

\section{Reference}

Ashing-Giwa, K. T., Kagawa-Singer, M., Padilla, G. V., Tejero, J. S., Hsiao, E., Chhabra, R., Martinez, L., \& Tucker, M. B. (2004). The impact of cervical cancer and dysplasia: A qualitative, multiethnic study. Psycho-Oncology, 12, 709-728.

Bird, J. A., McPhee, S. J., Ha, N. T., Le, B., Davis, T., \& Jenkins, C. N. (1998). Opening pathways to cancer screening for Vietnamese-American women: lay health workers hold a key. Preventive Medicine, 27, 821-29.

Chan, C. W. H., Molassiotis. A., Yam. B. M..C., Chan, S. J., \& Lam, C. S. W. (2001). Traveling through the cancer trajectory: Social support perceived by women with gynecologic cancer in Hong Kong. Cancer Nursing, 24, 387-94.

Chan, C. W. H. (2004). Social support and coping in Chinese patients undergoing cancer surgery. Cancer Nursing, 27(3), 230-236.

Chen, J. Y., Diamant, A. L., Kagawa-Singer, M., Pourat, N., \& Wold, C. (2004). Disaggregating data on Asian and Pacific Islander women to assess cancer screening. American Journal of Preventive Medicine, 27(2), 139-45.

Forbes, G. M., Fritschi, L., Mendelson, R. M., Foster, N. M., \& Edwards, J. T. (2004). Influences on participation in a community-based colorectal neoplasia screening program by virtual colonoscopy in Australia. Australia New Zealand Journal of Public Health, 28(3), 283-287.

Hiatt, R. A., Pasick, R. J., Stewart, S., Bloom, J.; Davis, P.; Gardiner, P. et al. (2001). Community-based cancer screening for underserved women: Design and baseline findings from the breast and cervical cancer intervention study. Preventive Medicine, 33, 190-203.

Hou, S., Fernandez, M., Baumler, E., \& Parcel, G. (2002). Effectiveness of an intervention to increase Pap test screening among Chinese women in Taiwan. Journal of Community Health, 27(4), $277-$ 290.

Hou, S., Fernandez, M., Baumler, E., Parcel, G., \& Chen, P. (2003). Correlates of cervical cancer screening among women in Taiwan. Health Care for Women International, 24(5), 384-398.

Hou, S., Fernandez, M., \& Parcel, G. S. (2004). Development of a cervical cancer educational program for Chinese women using Intervention Mapping. Health Promotion Practice, 5(1), 80-87.

Hou, S., \& Luh, W. (2005). Psychometric properties of the Cervical Smear Belief Inventory (CSBI) for Chinese women. International Journal of Behavior Medicine, 12(3), 180-191.

Jackson, J. C., Taylor, V. M., Chitnarong, K., Mahloch, J., Fischer, M., Sam, R., \& Seng, P. (2000). Development of a cervical cancer control intervention program for Cambodian American women. Journal of Community Health, 25, 359-375.

Jenkins, C. N., McPhee, S. J., Bird, J. A., Pham, G. Q., Nguyen, B. H., Nguyen, T. et al. (1999). Effect of a media-led education campaign on breast and cervical cancer screening among VietnameseAmerican women. Preventive Medicine, 28, 395-406.

Kelaher, M., Gillespie, A. G., Allotey, P., Manderson, L., Potts, H., Sheldrake, M. et al. (1999). The Transtheoretical model and cervical screening: Its application among culturally diverse communities in Queensland, Australia. Ethnicity \& Health, 4(4), 259-276. 
Kelly, A. W., Fores, C. M., Wollan, P. C., Trapp, M. A., Weaver, A. L., Barrier, P. A. et al. (1996). A program to increase breast and cervical cancer screening for Cambodian women in a midwestern community. Mayo Clinic Proceedings, 71, 437-44.

Kelsey, K. S., Campbell, M. K., Tessaro, I., Benedict, S., Belton, L., Fernandez, L. M. et al. (2000). Social support and health behaviors among blue-collar women workers. American Journal of Health Behavior, 24, 434-443.

Lam, T. K., McPhee, S. J., Mock, J., Wong, C., Doan, H. T., Nguyen, T. et al. (2003). Encouraging Vietnamese-American women to obtain Pap tests through lay health worker outreach and media education. Journal of General Internal Medicine, 18(7), 516-24.

Lee, T. F., Kuo, H. S., \& Chou, B. S. et al. (1997). Factors of Pap screening behavior among women in King-Men, Taiwan. Public Health of Republic of China, 16(3), 198-209.

Petersen, R., Graham, G., \& Quinlivan, J. A. (2005). Psychological changes after a gynecologic cancer. Journal of Obstetrics \& Gynecology Research, 32(2), 152-157.

Seow, A., Huang, J., \& Straughan, P. T. (2000). Effects of social support, regular physician and healthrelated attitudes on cervical cancer screening in an Asian population. Cancer Causes and Control, $11,223-230$.

Seow, A., Straughan, P. R., Ng, E. H., Emmanuel, S. C., Tan, C. H., \& Lee H. P. (1997). Factors determining acceptability of mammography in an Asian population: a study among women in Singapore. Cancer Causes and Control, 8, 771-779.

Sohn, L., \& Harada, N. D. (2005). Knowledge and use of preventive health practices among Korean women in Los Angeles County. Preventive Medicine, 41, 167-178.

Wang, P. D., \& Lin, R. S. (1996). Socio-demographic factors of Pap smear screening in Taiwan. Public Health, 110(2), 123-127.

Yang, Y. C., Chen, H. C., Lee, L. T., You, S. L., Hsieh, W. C., \& Chen, C. J. (1994). Family influence on cancer screening participation in seven communities in Taiwan. Journal of the Formosan Medical Association, 93(Suppl. 1), S56-64.

\title{
Acknowledgments
}

This study was supported by Cheng-Ching Hospital in Taichung, Taiwan. The authors gratefully acknowledge the assistance from the Department of Community Health and Department of Nursing in Chen-Ching Hospital on data collection and participant recruitment.

\author{
Author Information \\ Su-I Hou, DrPH, RN, CHES \\ Department of Health Promotion and Behavior \\ The University of Georgia, Athens \\ 309 Ramsey Center, 300 River Road \\ Athens, GA 30602 \\ Ph.: 706-542-8206 \\ Fax.: 706-542-4956 \\ E-Mail: shou@uga.edu \\ URL: http://www.uga.edu/publichealth/hpb/dept/hou.html
}

